Vol. 3 No. 1, Februari 2021, hlm. 278 - 284

\title{
RANCANG BANGUN E-LEARNING BERBASIS WEB PADA SMK NEGERI 3 SUMBAWA
}

\author{
Herfandi $^{1}$, Arman Diansyah ${ }^{2}$, Eri Sasmita Susanto ${ }^{3}$ \\ 1), 2), 3) Program Studi Teknik Informatika, Universitas Teknologi Sumbawa \\ email: ${ }^{1}$ herfandi@uts.ac.id
}

\begin{abstract}
Abstraksi: Telah banyak cara yang banyak dikembangkan untuk memperbaiki sistem pengajaran yang masih bersifat konvensional, yaitu Kegiatan Belajar Mengajar yang hanya dilakukan di dalam kelas. Namun terdapat beberapa sekolah yang sudah menerapkan sistem yang sedang berkembang yaitu dengan cara e-learning (pembelajaran secara online). E-learning dapat membantu para guru dalam mendistribusikan bahan ajar mereka tanpa harus berada di kelas dan juga dapat memaksimalkan waktu kegiatan belajar mengajar dengan cara mengggunakan layanan internet.

Rancang Bangun E-learning berbasis Website ini, diharapkan dapat membantu proses kegiatan belajar mengajar di SMK Negeri 3 Sumbawa menjadi lebih optimal. Metode ini memudahkan para guru untuk dapat menyampaikan materi pelajaran, memberikan tugas secara online, memberikan ujian secara online, pengumpulan tugas siswa secara online, dan siswa dapat melihat nilai secara online.
\end{abstract}

\section{Kata Kunci : Rancang Bangun, E-Learning, Website}

Abstract: There was developed many ways to improve the teaching system which is still conventional. That are the Teaching and Learning activities are only done in the classroom. But there are some of schools that have implemented a system that is growing is by way of e-learning. E-learning can help teachers in their teaching materials distributed without having to be in class and also can maximize the time of the Teaching and Learning Activities using the Internet service.

E-Learning design based on this Website, is expected to help the process of Teaching and Learning in Vocational High School of SMK Negeri 3 Sumbawa be more optimal. This method makes it easy for teachers to be able to convey the subject matter, give assignments online, give online exam, the collection of online student assignments, and students can view grades online.

\section{Keywords : Design, E-Learning, Website}

\section{PENDAHULUAN}

SMK Negeri 3 Sumbawa masih menggunakan metode konvensional yang kegiatan belajar mengajarnya di dalam kelas secara tatap muka pada waktu dan tempat yang sama. Dimana dalam proses belajar mengajar siswa dan siswi tidak bisa mengakses materi pelajaran secara digital dikarenakan belum adanya media yang dapat menyimpan dan berbagi materi atau informasi secara digital, baik materi, tugas, ujian dan lainnya. Seperti yang diketahui, waktu belajar siswa disekolah kurang dari 8 jam perhari dalam seminggu, selain itu beberapa siswa memiliki kegiatan organisasi baik di dalam maupun diluar sekolah. Berdasarkan permasalahan diatas penulis menawarkan solusi untuk membangun E-Learning yang mana nantinya memungkinkan siswa dan siswi dapat belajar diluar atau di jam sekolah, memberi suasana yang berbeda

karena belajar tidak hanya didalam kelas saja, namun dengan adanya fasilitas website sehingga proses belajar megajar akan terasa lebih menyenangkan. E-Learning atau singkatan
Electronic Learning adalah sebuah proses pembelajaran yang berbasis Elektronik. Salah satu media yang digunakan adalah jaringan komputer, yang memungkinkan untuk dikembangkan dalam bentuk berbasis Website, sehingga kemudian dikembangkan ke jaringan komputer yang lebih luas yaitu Internet. Penyajian E-Learning berbasis Website ini bisa menjadi lebih interaktif, maka hal ini memungkinkan tidak adanya batasan waktu dan ruang untuk pengaksesannya, sehingga antara guru dan siswanya dapat saling melakukan suatu proses belajar mengajar tanpa saling bertatap muka. Berdasarkan latar belakang di atas maka penulis perlu untuk melakukan penelitian tentang "Rancang

Bangun E-Learning Berbasis Web Pada SMK Negeri 3 Sumbawa" guna untuk memudahkan para siswa dan siswi untuk mendapatkan pembelajaran yang lebih efektif untuk pelajaran sekolah.

\section{TINJAUAN PUSTAKA}

Beberapa penelitian mengenai sistem $E$ - Learning berbasis website yang telah dilakukan, antara lain : 
1. "Rancang Bangun Sistem Informasi E- Learning Berbasis Web Pada SMK Daarut Taufiq Tangerang", oleh Eka Wulansari Fridayanthie, Mochammad Abdul Azis, Aliffah Kusumaningrum 2018. Dalam penelitian tersebut, E-Learning yang di bangun mampu mengantisipasi kekurangan materi terhadap siswanya yang melakukan proses PKL ataupun guru yang berhalangan hadir, siswa dapat mengakses materi yang diberikan oleh guru kapan saja dan siswa dapat mengerjakan kuis untuk mendapatkan nilai tambahan

2. "E-Learning Sebagai Media Pembelajaran Berbasis Web Pada SMK N 4 Purworejo", oleh Diah Pradiatiningtyas, Suparwanto pada tahun 2017. Dalam penelitiannya sistem E-Learning tersebut dapat membantu siswa terbiasa menggunakan ujian berbasis kumputer, sehingga membantu kelancaran dalam mengerjakan ujian nasional berbasis komputer

3. "Perancangan Aplikasi E-Learning Berbasis Web Pada SMA Padamu Negeri Medan”, oleh Romindo pada tahun 2017. Dalam penelitiannya, sistem tersebut mudah digunakan dan penyampaian informasi dan materi yang berkaitan dengan kegiatan belajar mengajar dapat disampaikan secara luas, akurat, dan tepat waktu.

4. "Perancangan Sistem Informasi E-Learning Pada SMK Syubbanul Wathon Tegalrejo Magelang", oleh Dina Maulina, Bernadhed pada tahun 2017. Dalam penelitiannya sistem informasi $E$ - Learning berbasis web tersebut dapat memberikan informasi tentang sekolah, menguploud dan mendownload berbagai informasi yang berhubungan dengan materi pembelajaran sekolah, melaksanakan kuis atau ujian online, serta mengumpulkan tugas siswa secara online.

5. "Membangun Sistem Informasi E-Learning Perkuliahan STMIK Wicida Samarinda", oleh Basrie, Amelia Yusnita pada tahun 2018. Dalam penelitiannya Sisitem Informasi E-Learning yang dibangun mempermudah proses belajar mengajar dilingkungan kampus.

Penelitian- penelitian tersebut membahas sebuah proses yang sama berupa efektifitas belajar mengajar pada sebuah instansi pendidikan dan hal yang membedakan adalah fitur-fitur yang diterapkan pada setiap penelitian tersebut.

Rancang Bangun adalah gambaran dari sistem untuk menciptakan sistem baru atau memperbaharui sistem sebelumnya.

E-Learning adalah suatu cara baru dalam pembelajaran yang menggunakan teknologi informasi dan komputer serta rangkaian elektronik untuk menyampaikan isi pembelajaran.

Dengan E-Learning proses pengembangan pengetahuan tidak hanya terjadi didalam ruangan kelas saja, tetapi dengan bantuan peralatan komputer dan jaringan, para siswa dapat secara aktif dilibatkan dalam proses belajar mengajar.
Prototype didefinisikan sebagai alat yang memeberikan ide bagi pembuat maupun pemakai potensial tentang cara sistem berfungsi dalam bentuk lengkapnya, dan proses untuk menghasilkan sebuah prototype disebut prototyping.(Menurut Raymond McLeod, 2013).

Kelebihan Prototype

1. Komunikasi yang baik antar pengembang dan pelanggan.

2. Pelanggan mengetahui apa yang diharapkan sehingga penerapan lebih mudah.

3. Waktu pengerjaan lebih cepat.

Kekurangan Protoype

1. Proses analisis dan perancangan sangat singkat, sehingga kadang bentuk prototype yang dihasilkan tidak sesuai dengan perancangan awal.

2. Apabila melakukan perbaikan, kurang memperhatikan kualitas dan pemeliharaan jangka panjang.

3. Hubungan pelanggan dengan komputer yang disediakan mungkin tidak mencerminkan teknik perancangan yang baik.

Pemodelan sistem yang digunakan dalam merancang $E$ Lerning dalam penelitian ini menggunakan DFD (Data Flow Diagram). DFD atau yang biasa disebut DAD (Diagram Alir Data), memperlihatkan gambaran tentang masukan-proses - keluaran dari suatu sistem atau perangkat lunak, yaitu objek - objek data mengalir ke dalam perangkat lunak, kemudian objek - objek data itu akan ditransformasi oleh elemen - elemen pemrosesan, dan objek - objek data hasilnya akan mengalir keluar dari sistem atau perangkat lunak.

Dalam pemodelan basis datanya menggunakan ERD (Entitas Relation Diagram) untuk menunjukkan relasi antar tabel serta data apa saja yang dibutuhkan.

\section{METODE PENELTIAN}

Metode yang digunakan dalam penelitian ini yaitu metode pengumpulan data dan metode pengembangan perangkat lunak.

Metode yang digunakan untuk memperoleh sumber data dan informasi dalam pembuatan tugas akhir ini adalah sebagai berikut : 
1. Wawancara

Pada teknik ini penulis melakukan wawancara langsung dengan pihak sekolah tentang metode pembelajaran dan seputar E- Learning yang diharapkan untuk SMK Negeri 3 Sumbawa.

2. Observasi

Pada teknik ini penulis melakukan pengamatan secara langsung tentang metode pembelajaran pada SMK Negeri 3 Sumbawa. Sehingga dapat di ketahui dan di analisis kebutuhan yang nantinya dapat dijadikan sebagai bahan untuk pembuatan E-Learning.

3. Studi Pustaka

Studi kepustakaan merupakan metode pengumpulan data yang dilakukan dengan cara mengumpulkan data dan informasi yang relevan dengan topik atau masalah yang sedang diteliti. Informasi tersebut dapat ditelaah dari buku, literatur, jurnal ilmiah, tesis, maupun dari internet. Pada penelitian ini, penulis mencari dan mengumpulkan referensi dari jurnal ilmiah, skripsi sebelumnya, maupun internet yang sesuai dengan topik penelitian sebagai bahan pendukung penelitian.

Setelah tahap pengumpulan data selesai dilakukan maka tahap selanjutnya adalah Pengembangan Perangkat Lunak. Software Development Life Cycle (SDLC) dengan model Prototype. Prototype terdiri dari tujuh tahapan yaitu analisis kebutuhan, pembuatan prototype, evaluasi prototype, pengkodean sistem, pengujian sistem, evaluasi sistem, dan penggunaan sistem. Pada metode prototype, pengembang dan user dapat saling berinteraksi selama proses pembanguna sistem, sehingga apabila terjadi kesalahan dapat langsung di evaluasi.

Adapun kebutuhan pengguna dalam E-Learning di SMK Negeri 3 Sumbawa ini sebagai berikut.

Tabel 1. Kebutuhan Pengguna (user)

\begin{tabular}{|c|c|c|}
\hline No & Pengguna & Hak Akses \\
\hline 1 & Guru & $\begin{array}{l}\text { Dapat melakukan } \\
\text { penambahan, perubahan, dan } \\
\text { penghapusan data yang ada pada } \\
\text { sistem terdiri dari data guru, data } \\
\text { siswa, kelas, mata pelajaran, data } \\
\text { tugas, pengumpulan tugas, data } \\
\text { ujian, dan data nilai }\end{array}$ \\
\hline 2 & Siswa & $\begin{array}{l}\text { Dapat mendownload materi } \\
\text { pelajaran dan tugas. } \\
\text { - } \quad \text { Dapat mengumpulkan tugas } \\
\text { - } \\
\text { - } \begin{array}{l}\text { Dapat mengerjakan ujian } \\
\text { dan ujian yang diberikan. }\end{array}\end{array}$ \\
\hline
\end{tabular}

Analisis Kebutuhan Data

Dalam membangun E-Learning di SMK Negeri 3 Sumbawa ini dibutuhkan data-data yang akan digunakan dalam layanan sistem tersebut.

1. Data Guru : Data guru adalah data yang menampung data identitas dari setiap guru mata pelajaran
2. Data Siswa : Data guru adalah data yang menampung data identitas dari setiap guru Mata pelajaran.

3 Data Mata Pelajaran : Data mata pelajaran adalah data yang berisi tentang detail mata pelajaran bagi setiap kelas.

4 Data Kelas : Data yang berisi kelas-kelas yang ada di SMK Negeri 3 sumbawa.

5 Data Tugas : Data tugas adalah data yang berisi tentang tugas-tugas yang telah di uploud oleh guru dari setiap mata pelajaran berdasarkan kelas ajaran.

6 Data Pengumpulan Tugas : Data pengumpulan tugas adalah data yang berisi tentang tugas-tugas yang telah di input oleh siswa.

7 Data Ujian : Data ujian adalah data yang berisi tentang ujian yang telah di uploud oleh guru dari setiap mata pelajaran berdasarkan kelas ajaran.

8 Data Nilai : Data nilai adalah data yang berisi tentang penilaian dari guru terhadap siswa atas tugas dan ujian yang telah dikerjakan

\section{Waktu Penelitan}

Dalam merancang dan membangun E-Learning ini, dibutuhkan rentang waktu bagi penulis untuk menyelesaikan skripsi ini yaitu selama 6 (enam) bulan terhitung dari bulan Juli hingga Desember 2020.

\section{Tempat Penelitan}

Dalam marancang dan membangun E-Learning ini, lokasi yang digunakan penulis dalam melakukan kegiatan penelitian berada di SMK Negeri 3 Sumbawa yang berlokasi di JL. Unter Iwes, No 1, Kerato, Kecamatan Unter Iwes, Kabupaten Sumbawa, Nusa Tenggara Barat, 84316.

\section{HASIL DAN PEMBAHASAN}

Adapun penerapan hasil dari metode prototype yang telah diterapkan sampai dengan pengujian sistem pada penelitian ini dibagi atas pembahasan hasil perancangan sistem dan pembangunan aplikasi E-Learning yang telah dilakukan.

\section{Perancangan Sistem}

Perancangan sistem dapat diartikan gambaran atau sketsa dari alur proses sistem pengolahan data. Dalam Rancang Bangun E-Learning Berbasis Web ini menggunakan Data Flow Diagram (DFD) dan Entity Relationship Diagram $(E R D)$. 


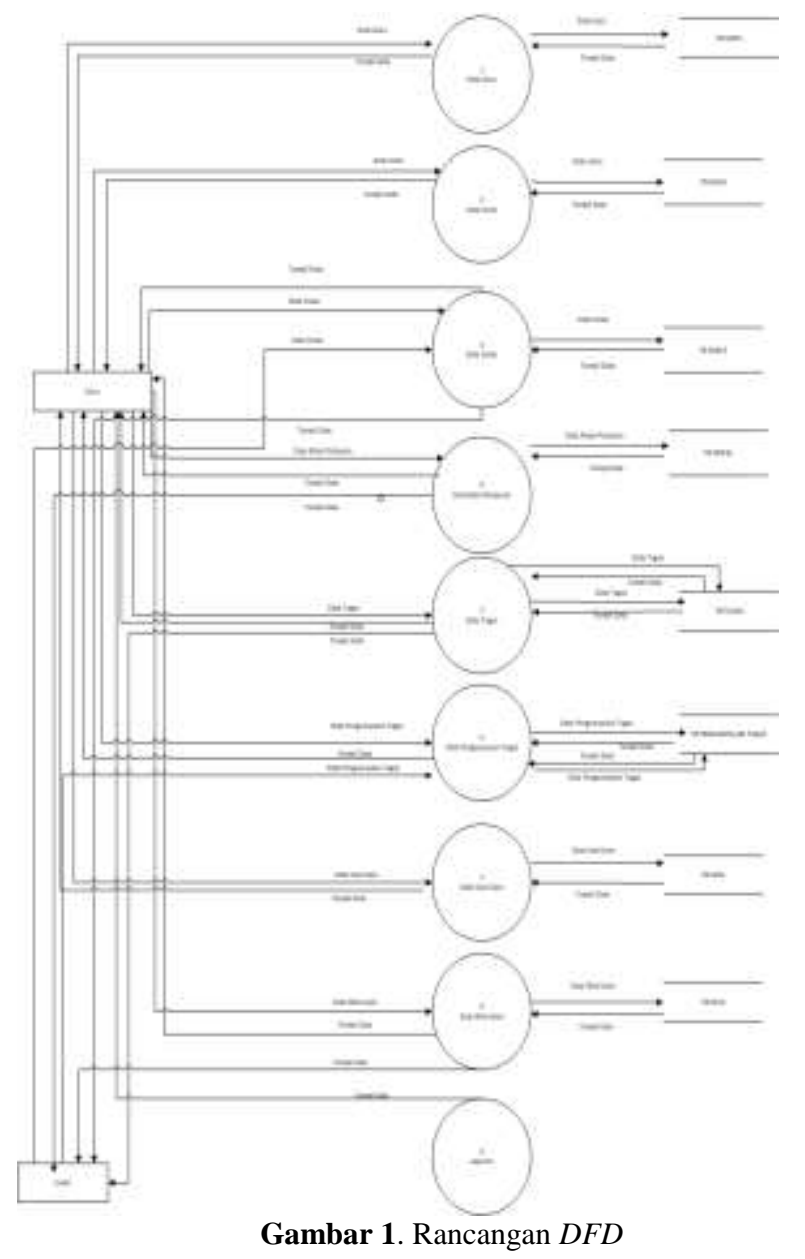

Entity Relational Diagram berfungsi untuk merancang database sebelum database tersebut dibuat. Pada ERD ELearning SMK Negeri 3 Sumbawa yang diusulkan, terdapat 8 entitas, yaitu User, Guru, Kelas, Siswa, Mata Pelajaran, Soal, Tugas, Nilai. Hubungan antara Siswa dan Tugas adalah many to many, dari hubungan tersebut menghasilkan tabel baru yaitu tabel Kumpul Tugas. Dari $E R D$ tersebut dapat disimpulkan bahwa database akan memiliki 9 tabel yang terdiri dari delapan tabel master, dan satu tabel detail.

Gambar 2. Rancangan $E R D$

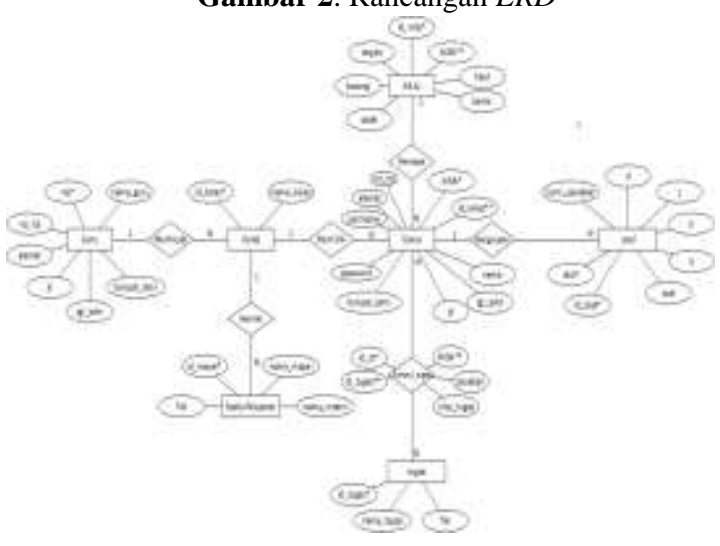

Terdapat dua tahapan dalam pembuatan program yaitu perancangan database dan perancangan interface. Database sebagai tempat penyimpanan (storage) untuk data - data yang disimpan. Mulai dari pada saat login sampai proses dan output data. Sedangkan interface sebagai tampilan yang merupakan jembatan antara user dan sistem.

\section{Perancangan Database}

Dalam pembuatan sistem ini, database yang digunakan adalah aplikasi $M y S Q L$. Langkah awal yaitu pembuatan database dengan nama e- learning smk negeri 3 sumbawa. Selanjutnya yaitu pembuatan tabel serta komponen atributnya. Dalam sistem informasi $e$ - learning ini terdapat 9 tabel yang dibuat.

\section{Implementasi Program \\ Halaman Login Guru}

Berikut ini adalah gambar tampilan awal ketika guru akan masuk dan mengakses panel guru dan operator.

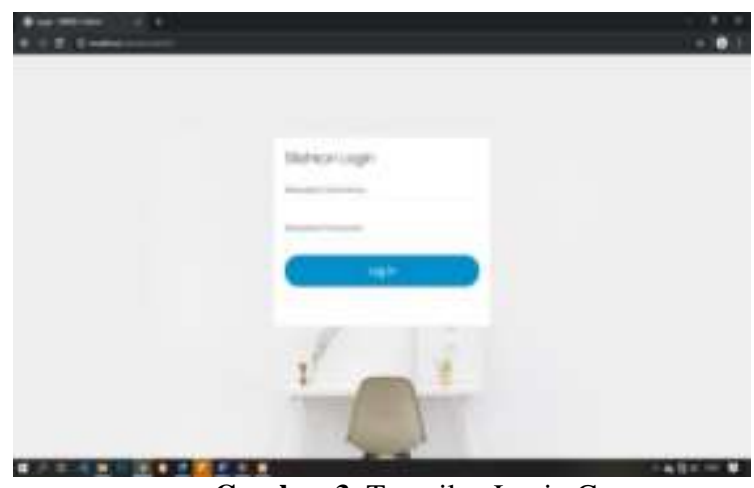

Gambar 3. Tampilan Login Guru

\section{Tampilan Menu Utama Guru}

Gambar halaman utama guru setelah melakukan login. Pada halaman dashboard guru dapat melihat dan mengelola data guru, data kelas, data siswa, data mata pelajaran, data tugas, data pengumpulan tugas, data soal ujian, data nilai ujian, dan laporan-laporan.

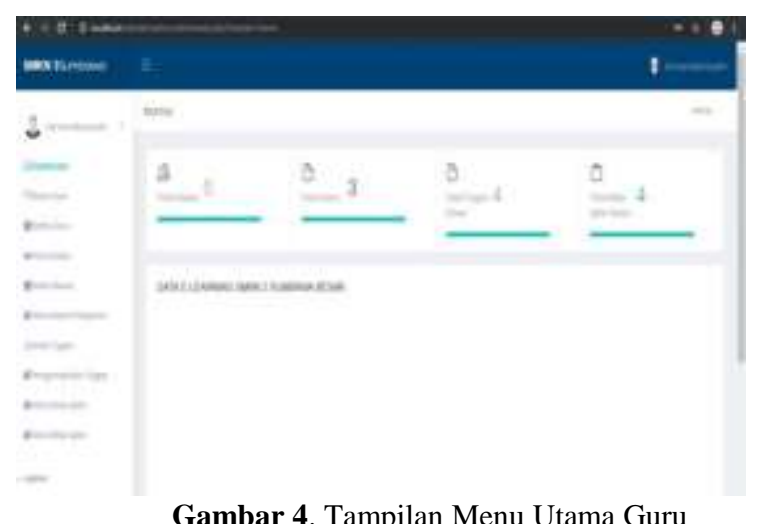

\section{Tampilan Data Soal Ujian}

Halaman data soal ujian digunakan sebagai halaman untuk menampilkan data soal ujian. Di dalam halaman ini terdapat 3 pilihan yaitu edit data, tambah data, dan hapus data. 


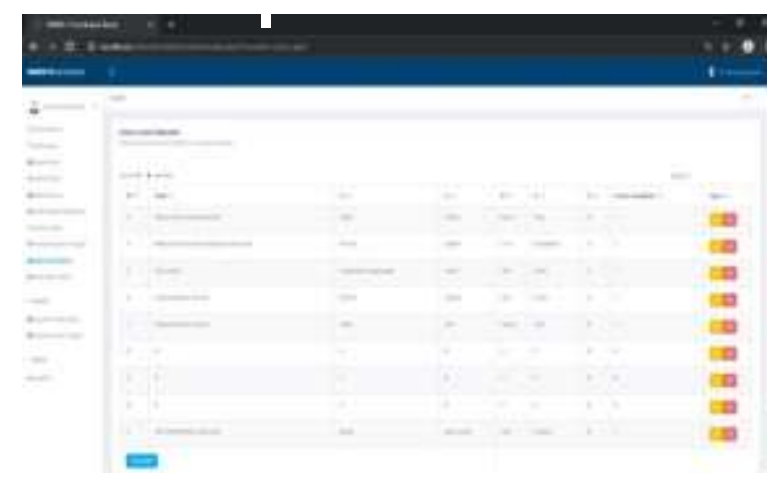

Gambar 5. Tampilan Menu Soal Ujian

Tampilan Data Nilai Ujian

Halaman data nilai ujian digunakan sebagai halaman untuk menampilkan data nilai ujian. Di dalam halaman ini terdapat 1 pilihan yaitu hapus data.

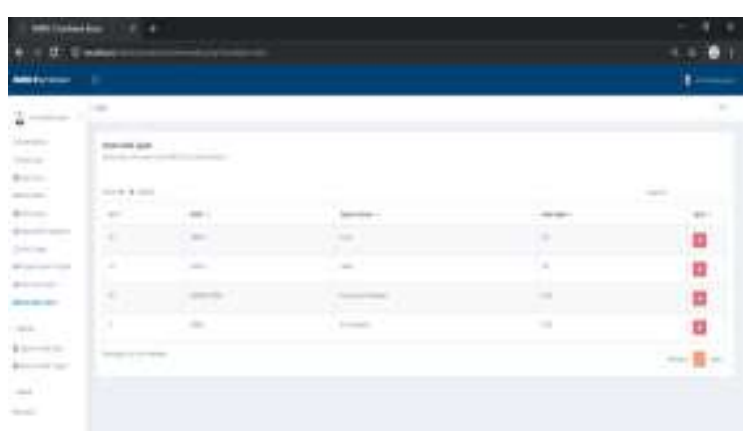

Gambar 6. Tampilan Menu Nilai Ujian

Halaman Login Siswa

Halaman ini adalah halaman pertama saat mengakses halaman siswa

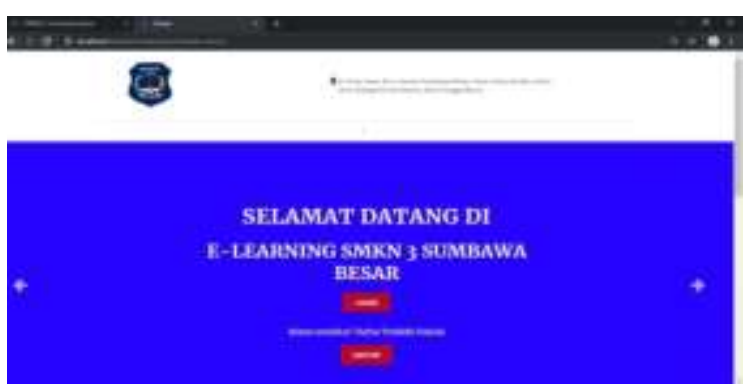

Gambar 7. Tampilan Login Siswa

\section{Halaman Biodata Siswa}

Halaman ini adalah tampilan biodata siswa

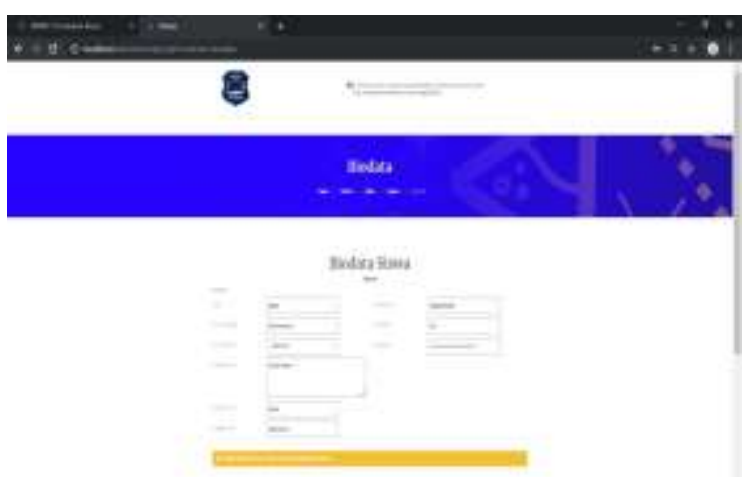

Gambar 8. Tampilan Biodata Siswa
Halaman ini adalah tampilan ujian siswa, agar siswa dapat menjawab ujian yang di berikan oleh guru.

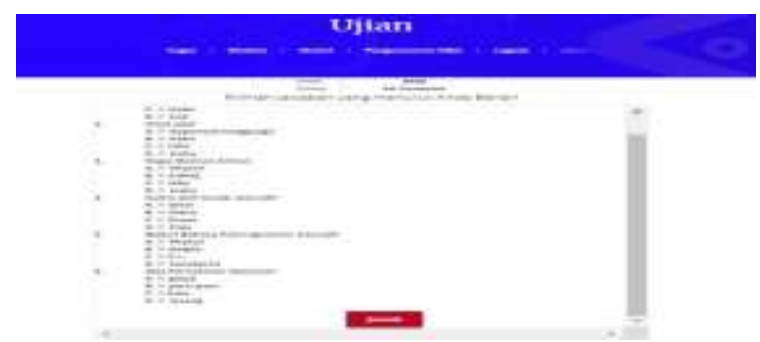

Gambar 9. Tampilan Menu Ujian Siswa

Tampilan Data Nilai Ujian

Halaman ini adalah tampilan nilai siswa, agar siswa dapat melihat nilai yang di berikan oleh guru.

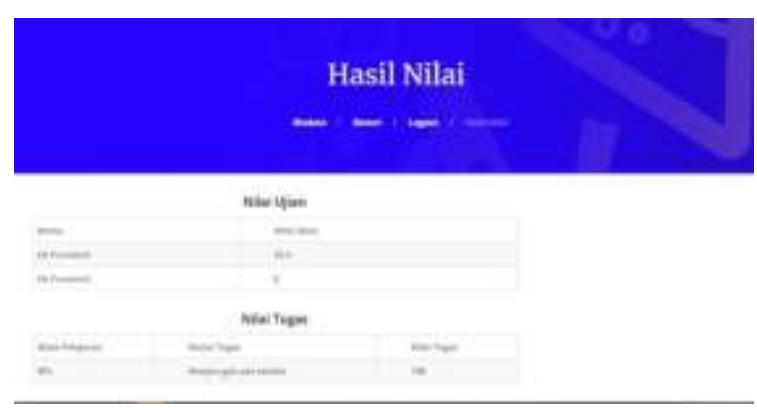

Gambar 10. Tampilan Menu Nilai Ujian Siswa

\section{Pengujian Sistem}

Pengujian yang dilakukan yaitu pengujian Black Box dan dibagi menjadi 2 (dua) yaitu pengujian pada sistem gurudan sistem siswa.

\section{Pengujian Sistem Guru}

Tabel 2. Pengujian Login Guru

\begin{tabular}{|c|c|c|c|}
\hline \multicolumn{4}{|c|}{ Kasus dan Hasil Uji } \\
\hline Aksi Aktor & Diharapkan & Pengamatan & Kesimpulan \\
\hline $\begin{array}{l}\text { Memasukk } \\
\text { an } \\
\text { Username } \\
\text { dan } \\
\text { Password } \\
\text { yang telah } \\
\text { tersimpan } \\
\text { di } \\
\text { database. }\end{array}$ & $\begin{array}{l}\text { Login } \\
\text { Berhasil } \\
\text { dan masuk } \\
\text { ke halaman } \\
\text { menu } \\
\text { utama }\end{array}$ & $-1-1$ & Sesuai \\
\hline $\begin{array}{l}\text { Memasukk } \\
\text { an } \\
\text { Username } \\
\text { dan } \\
\text { Password } \\
\text { yang salah. }\end{array}$ & $\begin{array}{l}\text { Login } \\
\text { Gagal dan } \\
\text { akan } \\
\text { muncul } \\
\text { notifikasi } \\
\text { "Login } \\
\text { Gagal, } \\
\text { Username } \\
\text { dan } \\
\text { Password } \\
\text { anda salah. }\end{array}$ & We & Sesuai \\
\hline
\end{tabular}


Tabel 3. Pengujian Menu Data Soal Ujian

\begin{tabular}{|c|c|c|c|}
\hline \multicolumn{4}{|c|}{ Kasus dan Hasil Uji } \\
\hline Aksi Aktor & Diharapkan & Pengamatan & Kesimpulan \\
\hline $\begin{array}{l}\text { Memilih } \\
\text { data soal } \\
\text { ujian. }\end{array}$ & $\begin{array}{l}\text { Menampilka } \\
\text { n halaman } \\
\text { data soal }\end{array}$ & $\vdots$ & Sesuai \\
\hline $\begin{array}{l}\text { Menambah } \\
\text { kan data } \\
\text { menu soal } \\
\text { ujian. }\end{array}$ & $\begin{array}{l}\text { Data menu } \\
\text { soal ujian } \\
\text { bertambah }\end{array}$ & $\vdots$ & Sesuai \\
\hline $\begin{array}{l}\text { Mengubah } \\
\text { Soal yang } \\
\text { memiliki } \\
\text { ID Soal } 12\end{array}$ & $\begin{array}{l}\text { Soal } \\
\text { berubah }\end{array}$ & 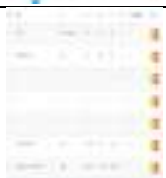 & Sesuai \\
\hline $\begin{array}{l}\text { Menghapu } \\
\text { s data soal } \\
\text { yang } \\
\text { memiliki } \\
\text { id soal } 5 .\end{array}$ & $\begin{array}{l}\text { Data yang } \\
\text { memiliki Id } \\
\text { soal } 5 \\
\text { terhapus }\end{array}$ & $\begin{array}{r} \\
\vdots \\
- \\
-\quad\end{array}$ & Sesuai \\
\hline
\end{tabular}

Tabel 4. Pengujian Menu Data Nilai Ujian

\begin{tabular}{|l|l|l|l|}
\hline \multicolumn{4}{|c|}{ Kasus dan Hasil Uji } \\
\hline Aksi Aktor & Diharapkan & Pengamatan & Kesimpulan \\
\hline $\begin{array}{l}\text { Memilih } \\
\text { data Nilai } \\
\text { Ujian }\end{array}$ & $\begin{array}{l}\text { Menampilka } \\
\text { n halaman } \\
\text { data nilai } \\
\text { ujian. }\end{array}$ & & Sesuai \\
\hline $\begin{array}{l}\text { Menghapu } \\
\text { s nilai } \\
\text { ujian yang } \\
\text { memiliki } \\
\text { Id 13 }\end{array}$ & $\begin{array}{l}\text { Nilai Ujian } \\
\text { yang }\end{array}$ & & \\
memiliki Id & & & Sesuai \\
\hline
\end{tabular}

\section{Pengujian Sistem Siswa}

Tabel 5. Pengujian Login Siswa

\begin{tabular}{|c|c|c|c|}
\hline \multicolumn{4}{|c|}{ Kasus dan Hasil Uji } \\
\hline Aksi Aktor & Diharapkan & Pengamatan & Kesimpulan \\
\hline $\begin{array}{l}\text { Memasukk } \\
\text { an } \\
\text { Username } \\
\text { dan } \\
\text { Password } \\
\text { yang telah } \\
\text { di inputkan }\end{array}$ & $\begin{array}{l}\text { Login } \\
\text { Berhasil dan } \\
\text { masuk ke } \\
\text { halaman } \\
\text { biodata } \\
\text { siswa }\end{array}$ & 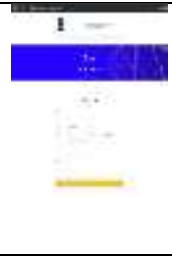 & Sesuai \\
\hline $\begin{array}{l}\text { Memasukk } \\
\text { an } \\
\text { Username } \\
\text { dan } \\
\text { Password } \\
\text { yang salah. }\end{array}$ & $\begin{array}{l}\text { Login } \\
\text { Gagal dan } \\
\text { akan } \\
\text { muncul } \\
\text { notifikasi } \\
\text { "Login } \\
\text { Gagal, } \\
\text { Username } \\
\text { dan } \\
\text { Password } \\
\text { anda salah }\end{array}$ & 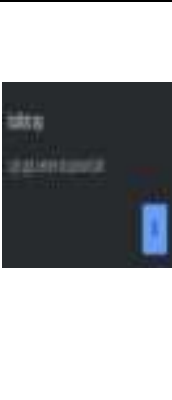 & Sesuai \\
\hline
\end{tabular}

Tabel 6. Pengujian Menu Ujian Siswa

\begin{tabular}{|c|c|c|c|}
\hline \multicolumn{4}{|c|}{ Kasus dan Hasil Uji } \\
\hline Aksi Aktor & Diharapkan & Pengamatan & Kesimpulan \\
\hline $\begin{array}{l}\text { Memilih } \\
\text { halaman } \\
\text { ujian. }\end{array}$ & $\begin{array}{l}\text { Menampilka } \\
\text { n halaman } \\
\text { ujian. }\end{array}$ & $1=$ & Sesuai \\
\hline $\begin{array}{l}\text { Mengerjak } \\
\text { an Soal } \\
\text { Ujian } \\
\text { dengan } \\
\text { memilih } \\
\text { jawaban. }\end{array}$ & $\begin{array}{l}\text { Masuk ke } \\
\text { rincian nilai } \\
\text { siswa }\end{array}$ & 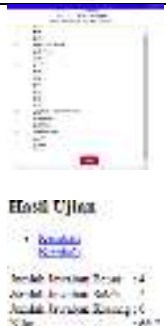 & Sesuai \\
\hline
\end{tabular}

Tabel 7. Pengujian Menu Pengumuman Nilai

\begin{tabular}{|l|l|c|l|}
\hline \multicolumn{5}{|c|}{ Kasus dan Hasil Uji } \\
\hline Aksi Aktor & Diharapkan & Pengamata & Kesimpulan \\
\hline $\begin{array}{l}\text { Memilih } \\
\text { halaman } \\
\text { pengumum } \\
\text { an nilai }\end{array}$ & $\begin{array}{l}\text { Menampilka } \\
\text { n halaman } \\
\text { pengumuma } \\
\text { n nilai. }\end{array}$ & $\ldots$ & Sesuai \\
\hline
\end{tabular}

\section{KESIMPULAN DAN SARAN}

Berdasarkan pembahasan pada halaman sebelumnya maka dapat ditarik kesimpulan :

1. Rancang Bangun E-Learning pada SMK Negeri 3 Sumbawa berbasis Web dalam penelitian ini sudah berhasil dibangun sesuai dengan perancangan sistem $D F D$ dan $E R D$.

2. implementasi program yang sudah dirancang dengan menggunakan Sublime Text sebagai toolsnya, bahasa pemrograman $P H P, \quad M y S q l$ sebagai databasenya, dengan menggunakan Black-Box sebagai pengujian sistemnya dan Terdapat dua level dalam mengakses sistem informasi ini, yaitu guru dan siswa.

Saran demi kesempurnaan penelitian ini adalah :

1. Penulis menyarankan agar peneliti selanjutnya mengembangkan sistem E- Learning berbasis mobile.

2. Penulis menyarankan agar peneliti selanjutnya lebih mematangkan pengujian sistem dengan menggunakan Black-Box.

3. Perencanaan dan pembiayaan harus dipikirkan terlebih dahulu sebelum merubah sistem yang baru.

4. Penambahan fitur-fitur akademik lainnya seperti rapot, sehingga bisa membantu dalam proses pengolahan nilai siswa.

\section{Daftar Pustaka}

[1] E. W. Fridayanthie, M. A. Azis, and A. Kusumaningrum, "Rancang Bangun (Sistem Informasi ELearning Berbasis Web Pada Smk Daarut Taufiq Tangerang," Swabumi, vol. 6, no. 2, pp. 123-127, 2018, 
doi: $10.31294 /$ swabumi.v6i2.4560

[2] D. P. dan Suparwanto, "E-Learning Sebagai Media Pembelajaran Berbasis Web Pada Smk N 4 Purworejo," Ijsn, vol. 7, no. 2, pp. 1-8, 2017, [Online]. Available: https://ijns.org/journal/index.php/ijns/article/do wnload/1499/1460.

[2] Basrie \& Amelia Yusnita. (2018). Membangun Sistem Informasi E-Learning Perkuliahan STMIK Wicida Samarinda : Sebatik, pp. 10-14.

[3] Romindo, "Perancangan Aplikasi E-Learning Berbasis Web Pada SMA Padamu Negeri Medan," J. Penelit. Tek. Inform., vol. Volume $2 \mathrm{~N}$, p. 6, 2017, doi: 10.1007/s13398-014-0173-7.2.

[4] Dina Maulina \& Bernadhed, "Perancangan Sistem Informasi E-Learning Pada SMK Syubbanul Wathon Tegalrejo Magelang," J. DASI Data Manaj. dan Teknol. Inf., vol. 18, pp. 8-13, 2017, [Online]. Available: http://library1.nida.ac.th/termpaper6/sd/2554/19 755.pdf.

[5] Basrie dan Amelia Yusnita, "Membangun Sistem Infromasi E-Learning Perkuliahan STMIK Wicida Samarinda," Sebatik, pp. 10-14, 2018.

[6] M. Z. Buchari, S. R. Sentinuwo, and O. A. Lantang, "Rancang Bangun Video Animasi 3 Dimensi Untuk Mekanisme Pengujian Kendaraan Bermotor di Dinas Perhubungan, Kebudayaan, Pariwisata, Komunikasi dan Informasi," J. Tek. Inform., vol. 6, no. 1, pp. 1-6, 2015, doi: 10.35793/jti.6.1.2015.9964.

[7] T. Y. Aslah, H. F. Wowor, and V. Tulenan, "Perancangan Animasi 3D Objek Wisata Museum Budaya Watu Pinawetengan," J. Tek. Inform., vol. 11, no. 1, 2017, doi: 10.35793/jti.11.1.2017.16922.

[8] G. Maulani1, D. Septiani, and P. N. F. Sahara, "Rancang Bangun Sistem Informasi Inventory Fasilitas Maintenance Pada Pt. Pln (Persero) Tangerang," ICIT J., vol. 4, no. 2, pp. 156-167, 2018, doi: 10.33050/icit.v4i2.90.

[9] K. Khamidah and R. A. Triyono, "Pengembangan Aplikasi E-Learning Berbasis Web Dengan Php Dan MySq1 Studi Kasus SMPN 1 Arjosari," IJNS-Indonesian J. Netw. Secur., vol. 2, no. 2, pp. 11-17, 2013, [Online]. Available: ijns.org..

[10] I. Maryo, "Analisis Pemanfaatan E-learning Sebagai Media Pembelajaran di Universitas Negeri Semarang ( UNNES )," no. 10142125, 2013.

[11] H. D. Herman Dwi, "The Evaluation of a Moodle Based Adaptive e-Learning System," Int. J. Inf. Educ. Technol., vol. 4, no. 1, pp. 89-92, 2014, doi: 10.7763/ijiet.2014.v4.375.

[12] Z. Zyainuri and E. Marpanaji, "Penerapan ELearning Moodle Untuk Pembelajran Siswa Yang Melaksanakan Prakerin," J. Pendidik. Vokasi, vol. 2, no. 3, pp. 410-426, 2012, doi: 10.21831/jpv.v2i3.1046.

[13] S. SHARIPUDDIN, E. EFFIYANDI, and D. FEBRYANTO, "Perancangan Aplikasi ELearning Pada Mts Negeri 1 Merangin," J. Process., vol. 14, no. 1, pp. 74-88, 2019, doi: 10.33998/processor.2019.14.1.576.

[14] M. S. Khairunnisa, "Pemanfaatan E-Learning
Bagi Para Pendidik Di Era Digital 4.0,” J. Sos. Hum. Sigli, vol. 2, no. 2, pp. 35-41, 2019, doi: 10.47647/jsh.v2i2.169.

[15] R. Jr, "Sitem Informasi Manajemen," Sist. Inf. Manaj., 2001.

[16] E. Sutanta, "Basis Data Dalam Tinjauan Konseptual," 2011.

[17] D. Sukrianto, "Penerapan Teknologi Barcode pada Pengolahan Data Pembayaran Sumbangan Pembinaan Pendidikan (SPP)," Intra-Tech, vol. 1, no. 2, pp. 18 27, 2017.

[18] Y. A. Pratama and E. Junianto, "Sistem Pakar Diagnosa Penyakit Ginjal Dan Saluran Kemih Dengan Metode Breadth First Search," J. Inform., vol. 2, no. 1, pp. 212-221, 2015, doi: 10.31311/ji.v2i1.69.

[19] D. Febiharsa, I. M. Sudana, and N. Hudallah, "Uji Fungsionalitas (BlackBox Testing) Sistem Informasi Lembaga Sertifikasi Profesi (SILSP) Batik Dengan AppPerfect Web Test Dan Uji Pengguna," JOINED J., vol. 1, no. 2, pp. 117-126, 2018, [Online]. Available: http://ejournal.ivet.ac.id/index.php/jiptika/article/view/ 752.

[20] Muhammad Rudyanto Arief, Pemrograman Web Dinamis Menggunakan PHP dan MySQL. Yogyakarta: Penerbit Andi, 2011.

[21] Nofyat, A. Ibrahim, and A. Ambarita, "Information Systems Water Custumers Complaints Web-Based on Pdam Ternate City," Ijis Indones. J., vol. 3, no. 1, pp. 10-19, 2018.

[22] N. S. S. Ilham Ishak, "SISTEM INFORMASI PROFIL BERBASIS WEB SEBAGAI MEDIA PROMOSI PADA WATERBOOM KOTA TERNATE," IJISIndonesia J. Inf. Syst., vol. 1, no. 1, pp. 21-30, 2016, [Online]. Available: https://media.neliti.com/media/publications/260171sistem-informasi-pengolahan-data-pembelie5ea5a2b.pdf.

[23] Alexander F. K. Sibero, Web Programming Power Pack. Yogyakarta: Mediakom, 2013.

[24] Budi Raharjo, Belajar Otodidak Membuat Database Menggunakan MySQL. Bandung: Informatika, 2011.

[25] Abdul Kadir, Pengenalan Sistem Informasi Edisi Revisi. Yogyakarta: Andi, 2017.

[26] V. P. Supono, Pemrograman WEB Dengan Menggunakan PHP dan Framework Codeigniter. Yogyakarta: Deepublish, 2016.

[27] M. Faridl, "Fitur Dahsyat Sublime Text 3," Lug Stikom, 2015.

[28] Y. Purbadian, No TitleTrik Cepat Membangun Aplikasi Berbasis Web Dengan Framework CodeIgniter. Yogyakarta: Andi, 2016.

[29] G. Ramadhani, "Internet Apa Itu Internet?," Pengenalan Internet, p. 24, 2003, [Online]. Available: http://directory.umm.ac.id/tik/pengenalan_internet.pdf.

[30] W. Komputer, Seri Panduan Lengkap Pemrograman HTML 4.1. Yogyakarta: Andi, 2003. 